\title{
Female, Mosher, Transgressor: A 'Moshography' of Transgressive Practices within the Leeds Extreme Metal Scene
}

\author{
Gabrielle Riches, Brett Lashua and Karl Spracklen \\ Leeds Metropolitan University \\ G.Riches@leedsmet.ac.uk/B.Lashua@leedsmet.ac.uk/K.Spracklen@leedsmet.ac.uk
}

\begin{abstract}
This paper examines and reconceptualises transgression in the Leeds extreme metal music subculture through theories of performance, embodiment and spectacle. The spectacle, for Debord (1967), is a social relation that is alienating and mediated by images and technology. At a live extreme metal concert fans subvert social norms, challenge gendered expectations, and disregard hegemonic norms of etiquette and decency. Moshing is the most visible and sensuous example of transgression within the extreme metal scene. It is an aggressive, physically demanding performance which embodies resistance to the impersonal and disillusioning world of the spectacle (Halnon 2004). The pit is a transgressive space that is itself transgressed by women who participate in this masculine, chaotic space, disrupting the homosocial bonds of male solidarity (Gruzelier 2007). This paper offers an ethnographic account of a female metal fan participating in the transgressive practice of moshing within the Leeds metal music scene---a moshography.
\end{abstract}

Keywords: Moshpits, spectacle, embodiment, transgression, performance ethnography, extreme metal music

\section{Introduction}

As I jump into the moshpit arms and elbows are flying, blurs of long hair whipping back and forth; chests and shoulders driving into me, anonymous boots crushing my shoes; sweat dripping, hearts pounding... distorted guitars vibrate the walls, blast beats cannonade from the drums, guttural growls are disgorged into a microphone...mesmerised by the imperious sound, the dizzying swirl of movement, a maelstrom of bodies adorned in black shirts slamming arbitrarily into one another, alive and attuned to the smells of stale beer, cigarette smoke, sweaty leather, unwashed bodies. Some might say it's no place for a woman; but it's the place for me (Author 1, field notes, August 2012).

In the moshpit, transgression against hegemonic norms is embodied by practices, fashions and attitudes. This paper provides an account of such transgressive practices and encounters through an ethnography of the moshpit, a "moshography". It builds upon the on-going research of the lead author, who is embedded in the Leeds extreme metal scene as a female researcher, ethnographer and participant-observer. The paper 
begins with a brief overview of extreme metal and the literature on transgression and gender in heavy metal. We then set out a justification of the context, practice and ethics of moshography, before using fieldwork case studies from the Leeds extreme metal scene to explore trangressive practices and spectacles in more detail: the embodiment of transgression, how women actively transgress the space of the moshpit and reflections on being a female stage diver. Although we acknowledge that transgressions within extreme metal are always already related to wider shifts in cultural and social practices, we are particularly concerned with the internal gendered negotiations in the Leeds metal scene. Therefore, in the conclusion, we return to the question of agency and suggest that although extreme metal is a site for a polyvalent reading of performativity and transgression, such readings are intrinsic to the Leeds extreme metal scene, and as such their transformative potential in wider society remains uncertain. Before we discuss extreme metal, it is necessary to consider our theoretical framework in more detail.

Our theoretical framework is informed by the work of Debord (1967). The spectacle, according to Debord (1967), is a social relation that is alienating and mediated by images and technology. He maintains that the spectacle blurs the distinction between true and false, self and world, and real and illusion. Spectacles are those phenomena of commercialised culture that embody contemporary society's basic values, serve to adapt individuals into its way of life, and dramatise its conflicts and modes of conflict resolution. Debord asserts that the spectacle is a sham because it merely constructs the illusion of community, thus masking class and gender inequalities. The spectacle structures and reflects dominant ideologies that are assumed as natural and neutral (Gilman-Opalsky 2008). Being part of the Situationist International (SI) revolutionary group, Debord and others advocated that the commodity of the spectacle could be undermined and transformed through creating rebellious artistic situations. These situations consisted of performances and other innovative demonstrations that shifted peoples' interpretation of the world away from complacency, conformity and acceptance. Debord argued that these emerging unexpected, situated disruptions and ruptures reach people on an emotional (sensual) level which then create spaces for critique and social cohesion.

Yet the idea of the spectacle does not have to be reduced to a pessimistic, totalitarian Debordian vision. Kellner's (2003) work on spectacle emphasises the possibilities of contradictions, conflicts, and resistance; suggesting that spectacles are contested territories, pluralistic and heterogeneous sites of resistance and transgression. The idea that the spectacle can be resisted while also being a site of resistance is brought up in Halnon's (2004: 746) work on the shock music carnival. She contends that within this liminal world of the grotesque fans resist a society of the spectacle by turning to something more localised and personalised. What is paradoxically fascinating is how fans escape the mundanity of the commercialised spectacle by consuming a more underground, transgressive spectacle. Additionally, the spectacle becomes a transformative space in which these mundane social relations are embodied. Maffesoli (1996: 77) accounted for the orgiastic experience of the spectacular in that the nature of the spectacle is to "accentuate, either directly or by euphemism, the sensational, tactile dimension of social existence". In other words, people's bodily pleasures are derived from the pleasures found in being immersed in a crowd. For Maffesoli these collective forms of embodiment and corporeality are significant aspects of community building. In his discussion on sport and the spectacle, Tomlinson (2002) notes that Debord's theorisation of the spectacle fails to account for the pleasurable, playful and fun dimensions within consumer culture. According to Tomlinson (2002), mainstream spectacles such as sport produce a variety of subcultural practices which can be positive forms of sociability and collective affirmation. This provides another theoretical layer to the spectacle in that commercial enterprises actually produce subcultural forms of resistance which then rebel against 
the enterprise itself. In the next section, we examine how subcultural spectacle functions as resistance, rebellion and transgression within the Leeds extreme metal music scene.

\section{Extreme Metal: Encountering a Subcultural Spectacle}

Extreme metal, which is comprised of subgenres such as thrash, death metal, black metal, and grindcore remains on the edge of traditional heavy metal culture. These marginal forms of heavy metal are considered by some to be the most dynamic, artistically diverse, and transgressive (Kahn-Harris 2007). Scholars have argued that black metal - unlike other forms of extreme metal - provides a creative space for the production and maintenance of extremist ideologies and transgressive practices associated with elitism (Lucas 2010; Spracklen, Lucas and Deeks 2012); however, such transgressions are often linked to the carnival of Satanism, and gay artists such as Gaahl of the black metal band Gorgoroth, who have tried to use the music to challenge heteronormative boundaries have found themselves ostracised (Spracklen 2010). Remarkably, some of the Norwegian black metal bands from the second-wave black metal movement exceeded the carnivalesque by using the genre as a springboard for real acts of violence and murder. Kahn-Harris (2007) views all forms of extreme metal as being equally part of a marginal, underground scene where individualism and anti-conformity are privileged over the commercial interests of mainstream heavy metal (and rock and pop music). It is this view of extreme metal that we follow here.

Extreme metal as a subcultural spectacle is structured by particular ideologies that create a sense of community through discrete but poignant mechanisms of gender inequality. These hegemonic structures are so prevalent that they have become part of extreme metal's architecture where authentic performances and representations of extreme metal are presumed to be masculine. For example, in Leblanc's (1999) ethnographic study about women's involvement in punk music (like heavy metal, a transgressive form of rock music), it was evident that many women felt pressured to adhere to hegemonic masculine codes, scripts and practices (such as dressing masculine, playing aggressively on stage) in order to avoid further marginalisation. In Hutcherson's (2009) research on gender performativity and authenticity within the death metal scene of Bluff City, he noticed that there were visible divisions of space (both physical and social) which were directly influenced by gender. Men tended to dominate central spaces within the venues such as on stage, in the moshpit, and directly in front of the stage. Comparable to the Janus-faced nature of the spectacle, extreme metal is deceptive in that the subcultural community prides itself on being transgressive while simultaneously reinforcing hegemonic understandings of gender relations and norms (Krenske \& McKay 2000). Even though extreme metal's defining features such as its musical style, lyrics, clothing style and overall audience demographic are no doubt culturally coded as male, Bogue (2004) argues that the music, particularly death metal, evokes such strong sensual intensities of the body that metal's "masculine" character is deprived and weakened through exaggerated gestures.

For some subcultural researchers like Williams (2011), subcultural spaces such as extreme metal are seen as potential sites for women to engage in transgressive practices. Subcultural spaces and scenes can offer women alternative ways of performing and playing with gendered identities compared to what is available in the mainstream. According to Hutton (2006: 8), whose scholarly work examined gender performance in alternative club spaces, "women take part in cultures and spaces that render them visible in public and which also label them quite clearly as participants in these cultures and spaces." Lau (2005) and Riches (2011), who have explored the gender dynamics of moshpit participation, found that women embraced the masculinised, physically demanding, chaotic space of the moshpit as a site of 
empowerment because they were, through the use of movement and bodily interaction, transgressing stereotypical assumptions associated with femininity (passivity, requiring protection, gentle) within the metal scene and dominant society. The moshpit, then, becomes an important mechanism in which typically "invisible" female fans render themselves as visible and forceful subcultural members.

Transgression, like extremity, implies a sense of testing and disrupting boundaries. In this paper we draw upon Bataille's $(1986,1989)$ notion of transgression, which is experienced bodily and flirts with death and the erotic, and invites both repulsion and desire. Transgressive practices engage with and transcend taboos and according to Bataille (1986) social life as we know it is defined through organised transgressions. Ironically, transgression often involves creating new boundaries as it simultaneously destroys others. Popular music is paradoxically both conformist and transgressive. The history of popular music is replete with celebrated examples of transgression, such as the "crossover" of established "musico-racial boundaries" in the music of Michael Jackson (Roberts 2011: 21), Elvis (Bertrand 2000) and Eminem (Dawkins 2009). Other highly successful commercial artists such as Madonna and Lady Gaga (Broek 2012), the Spice Girls (Lemish 2003), and Alanis Morissette (Schlit 2003) have been lauded where their music transgressed established gender norms. The power and potential of transgression was described by Duncum (2009: 234) as "another kind of pleasure, that of jouissance, an intense, blissful ecstasy produced by evading and transgressing the social order" that allows a playful inversion of gender hierarchies, sexualised stereotypes, violence/humour, and other binaries. Introducing a 2012 special issue of Popular Music History devoted to metal music, Hjelm, Kahn-Harris, and LeVine (2012: 6) noted that "the transgressive aspects of metal make it antagonistic in different social contexts". Klypchak (2012: 38) argued that early metal artists such as Alice Cooper, Black Sabbath and Kiss "pushed the bounds of perceived social propriety, sparking controversy" and a conservative backlash. Also writing in that issue, Overell argued that the "affective intensity" in grindcore music "potentially transcends representations of gender" (2012: 198). Whether pushing boundaries or transcending them, Hjelm, Kahn-Harris, LaVine further noted that "metal tends to be dominated by a distinctive commitment to 'transgressive' themes and musicality" that lend to its countercultural and controversial status (2012: 6). Extreme metal music challenges, disrupts and tests boundaries and limits of social conventions through transgressive play and performance. At a live metal concert fans subvert social norms, challenge gendered expectations, and disregard norms of etiquette and decency. Moshing is the most visible and sensuous example of transgression within the extreme metal scene.

Moshing is an aggressive, physically demanding practice which embodies resistance to the impersonal and superficial world of modernity (Halnon 2004). Moshing is considered to be an embodied, sensual subcultural practice within heavy metal music. It is demarcated by gendered performances, sporadic movements and implicit rules which govern particular behaviours that are seen by metal fans as jeopardising the safety of other metal fans within the self-contained space of the moshpit. The The moshpit is a socially constructed area in front of the stage where headbanging, crowd surfing, stage diving, body slamming, and aggressive pushing are encouraged and maintained. To "mosh" is a distinctive way of using the body to corporeally articulate individual and collective subcultural identities. It consists of bodies being touched, pushed, shoved, lifted, caught, picked-up, thrown and carried within a disordered, active moving space. The moshpit becomes transgressive when it fosters critique and rebellion of mainstream expectations, emotions, bodily interactions, and social relationships. Transgressive practices such as moshing, which erupt during a subcultural spectacle, allow metal fans the opportunity to experientially engage with their musical world, understand themselves and others through the use of the body, and physically disrupt extreme metal's ideological boundaries by challenging gender and social norms. Moreover, the pit is a space that is transgressed by women who 
participate in this masculine, chaotic space, disrupting the homosocial bonds of male solidarity (Gruzelier 2007).

\section{"Moshography": The Use of a Performative and Embodied Ethnography}

"Moshography" is a metaphoric, methodological practice and transgressive, subcultural form of expression. This ethnographic approach differs from conventional research methods about popular music and performance in that it draws attention to the embodied, sensual aspects of subcultural practices in the moshpit. In Morton's (2005) discussion on performance ethnography, she argues that this methodological approach centralises the sensory, non-verbal, and affective aspects of performance. Performance ethnography allows researchers to access, encounter and uncover temporary, embodied and fleeting social practices within musical spaces. Within the discipline of popular music there has been a lack of critical engagement with the senses and their relationship with space, identity, gender, and performativity. There have been some notable scholars who have employed innovative research methods in order to get at or flesh out the feeling of being part of a subculture and to experientially learn the skills to truly engage in subcultural practices (Driver 2011; Berger 1999). Driver (2011) explored the embodiment of subcultural identities within hard-core music, and emphasised that the knowledge required to successfully participate in a moshpit is something which is experientially "learned", something necessitating a mode of engagement with the music that is borne of a sensual competence rather than a discursive one. According to Sparkes and Smith (2012) there has been a revolution within the social sciences that has sought to re-embody qualitative research. By engaging with and through the senses, ethnographers are able to remain attentive to the emotional nature of embodiment as they actively use their bodies as tools of inquiry and sources of knowledge within the field. Stoller (1997) identified this approach as sensuous ethnography which is about reawakening the scholar's body by fusing the intelligible and the sensuous in scholarly practices and representations. It is about incorporating and being attentive to the smells, textures, tastes and sensations that are felt through the body and these sensual experiences are essential aspects to our ethnographic understandings within the field.

Because of the distinctive contexts, constraints, affordances and sensuousness of conducting ethnographic fieldwork in extreme heavy metal culture, we have coined the term "moshography" to encompass the unique ethnographic practices involved in Author 1's moshpit research. Denzin and Lincoln (2007: 4) refer to other creative qualitative practices of "montage, bricolage or quilt making" where the researcher "uses the aesthetic or material tools of his or her craft, deploying whatever strategies, methods and empirical materials are at hand.... If the researcher needs to invent, or piece together new tools or techniques, he or she will do so". Examples of inventive, mishmash patchwork as qualitative research include cinematic montage (Denzin, 2002), jazz (Oldfather and West 1994), swing (Spry 2010), torch singing (Holman Jones 2002), dance (Janesick 1998), poetry (Diversi 1998), and quilting (Flannery 2001). Along similar lines, Alim (2007) argued for an approach to hip-hop ethnography which echoed in "metaphoric" ethnographic fieldwork, e.g., "hiphopography" (Alim 2007: 163); Lashua and Fox (2007) referred to their ethnographic research making mash-ups of rap, metal, soundscape, country and traditional First Nations music as "remixology". Whether research as jazz improvisation, cinematic montage, or quilt making, the juxtaposition of many views, voices, movements and moments by the researcher helps to "create the sense that images, sounds, and understandings are blending, overlapping, forming a composite, a new creation" (Denzin and Lincoln 2007: 4). For us, this new research composition is a moshography.

Fieldwork is experience, and the experience of being fully immersed in the moshpit and participating in other extreme metal practices constitutes an embodied way of doing ethnography. Cohen (1993) emphasised that an ethnographic approach to the 
study of popular music involving direct observation of people, their interactions, and participation in their everyday performances would increase our knowledge of musical practices and processes. Cooley and Barz (2008) invited music ethnographers to be actively involved in musical practices and performances. Subsequently, Author 1's involvement in moshpit practices within the Leeds extreme metal scene has been her path towards gaining access to people within the subculture. The bruises on her arms from an aggressive pit are remnants of a lived and ever-changing subculture. The blackish blue imprint from clashing bodies onto her skin transforms from a painful encounter into an embodied recollection of gender transgression. The experience of being thrown, tossed, shoved, pushed, and disoriented in the moshpit is a transgressive yet vulnerable methodological practice because she is physically and emotionally forced to open herself up to the pleasures, pains, discomforts, challenges, and unexpected ruptures that encapsulate the everyday experiences of being a researcher, female metal fan, and mosher.

This article, drawn from a larger, on-going doctoral ethnographic research project, is based on ethnographic data gathered from February 2012 through February 2013. Author 1 conducted six in-depth interviews with female metal fans who are active moshpit participants and engage in everyday scene activities within the Leeds extreme metal music scene. Identifying as an authentic subcultural member of the metal community and having attended and participated in over 50 metal gigs, Author 1 met these female metal participants through the transgressive practice of moshing. Additionally, at each metal show she took extensive field notes that documented her own embodied experiences of moshing, the ways in which the women negotiated the physical space of the pit, gendered interactions, and the spatial distribution of women and men within each venue in Leeds.

Leeds, an industrialised city in the North of England, has a vibrant heavy metal scene despite being a victim to the 'postmodern project' (Bramham and Wagg, 2009) in which metal venues once located in the city centre have been pushed to marginal, residential areas in favour of more commercialised, mainstream leisure pursuits. The Leeds extreme metal scene is characterised as predominantly masculine, white, working class and heterosexual. As Author 1 became actively involved in the scene she became accustomed to seeing men performing on stage, setting up musical equipment, organising gigs, standing in the crowd, and participating in the moshpit. On the surface there seems to be a coherent, solidified Leeds metal scene but there are a number of segregated scenes within this subcultural canopy; the scene can be characterised as fluid, fleeting, vulnerable and multifaceted. As the production and consumption of local extreme metal music has relocated to the urban peripheries this has impacted the scene's coherence and the ways in which metal fans participate in underground, metal activities. In addition, the scene's fragmentation has made it difficult for women to remain distinctly visible in the local and wider metal scene. Nonetheless, there are many female transgressors who claim space in the centre of the moshpit, and thus position themselves at the centre of the Leeds extreme metal scene.

\section{Analysis and Discussion}

\section{Moshpit Immersion: What Transgression Feels Like}

The metal band started playing, the combination of the pulsing and furious blast beats and the guttural growl instantly absorbed me. The music took over my body and I felt as 
though the rhythm was embedded in my chest, loosening up my muscles, injecting adrenaline into my veins. The energy of the crowd intensified symbiotically as the music sped up; people began to move their heads, quite aggressively, in time to the music. The venue suddenly got hotter... wafts of newly washed, fragrant hair whipped past me. I was shoved into the middle where I collided with anonymous, masculine, sweating bodies; the venue became a blur as I spun around, my long brown hair assaulting my face as I was thrown in different directions sporadically. I was thrown towards the stage and then as I put my hands out to grab the monitor I spun around and lobbed myself in the opposite direction. I couldn't see faces, just bodies, arms, shoulders, elbows. My hand remained in front of me for protection and also to maintain balance as bodies brushed past me. I paced around the outside of the core of the pit in order to get some air and then tossed myself back into the nucleus of clashing bodies. As bodies collided into me I felt this palpable yet indescribable sense of friendship and camaraderie. I felt more attuned and connected to the people around me by the way in which I moved my body. As I immersed myself in the maelstrom of bodies, the venue felt as though it was transformed, once a dark, hollow almost lifeless venue into a space of visceral intimacy, inclusivity and pleasure (Author 1, field notes, July 2012).

Although there is a substantial amount of literature documenting the history of moshing, men's moshpit experiences, and moshing's role in various music subcultures (Ambrose 2001; Simon 1997; Tsitsos 1999; Palmer 2005) there has been little attention paid to women's participation in moshpit practices, particularly the embodied dimension of engaging in transgressive, subcultural practices. For the majority of the participants, discussing their feelings, emotions and embodied sensations in the pit was difficult, they were hard to explain or difficult to put into words. This difficulty in articulating musical and emotional experiences is echoed by Duffy (2005: 678), "such experiences are ephemeral and difficult to express in words. The emotions we experience in and through music are done so precisely because they cannot be expressed by any other medium". This is expressed by 'Hannah' when she attempted to explain what she feels when she is immersed in the pit:

It's too much energy so I gotta get it out [she raises her fists above her head, squeezes them tightly, and rapidly shakes them back and forth while closing her eyes]. It's hard to explain. You find yourself with too much energy, it's like adrenaline. It's not a fear; I'm not scared, I'm not angry. I'm pretty damn happy.

Moshing, as a practice, movement, embodied form of subcultural membership, and metaphor for the research, is best understood as non-representational. According to Thrift (2007), non-representational theory concentrates and takes seriously social practices and the spaces which practice opens up. It acknowledges that the body is essential in understanding our social worlds and ourselves as complex entities. Thrift (2007: 14) uses dance as a metaphor because it "engages the whole of the senses in bending time and space into new kinaesthetic shapes" and is also experimental, corporeal, and embodied. Many of the female moshpit participants used metaphoric language and incorporated corporeal references when they explained their moshpit experiences:

It's almost like being part of the music, you know, you're going up and down with the beat and you're bashing around. It's that big sense of communal energy. It's the camaraderie, the fun of it, the exhilaration. It's all hitting you in the stomach, people are bouncing around. It's that feeling of, you know that point when you've been drinking, you get so drunk that you're completely reckless but not in a dangerous way, you're carefree, everything's fine but you're safe. It's [the moshpit] is just like that ('Carole').

Carole's embodied moshpit account relates to Driver's (2011) work on subcultural embodiment in that these women come to know, through their corporeal interactions and movements, what it feels like to identify as a metal fan, transgress the moshpit and belong to the Leeds extreme metal scene. And when women embody the appropriate skills for moshing the anxieties about physical pain and injury dissipate because they do not have to think about moshing, they just do it: 
I saw the moshpit and I was like, that looks fun. And then I kind of worked myself up for a couple of songs and I was like right, okay, I can do this. I went in and it was awesome! I had so much fun. I can't explain, I literally didn't feel anything, physically, for the whole time. It's kind of like being extremely hyper in your head but not feeling any pain in general. I didn't feel anything; I was just so happy the entire time ('Allison').

Similar to Stoller's (1997) description of sensuous ethnography as a deeply felt engagement in the field where the research consumes the researcher and is reciprocally consumed by it, 'Shelly' described how metal music is first absorbed and then physically expressed in the moshpit:

It's more of if the music is stirring up something inside you and you can't just stand still and listen to it, you have to do something. Yeah it's feeding through and it's getting into your body and you have to have like a release of some sort. Every single time I mosh I connect with the band and the people around me on a deeper, more personal level. If I'm tired at a festival or something and if I get into a pit it always wakes me up, it always boosts my mood. I don't think I've ever come out of a pit and not felt elated in some way (Shelly).

The centrality of the body in the moshpit is echoed in Purcell's (2003: 69) description of the moshpit where "touch is electric and bodies are no longer constraints. What could better express the paradox of simultaneously being supremely alive and yet separated from the self as part of something shared." Utilising a moshography aims to capture the more "expressive, non-verbal, expressive and emotive, non-cognitive aspects of social practice and performance" (Morton 2005: 663), and in this case, the more embodied and affective features of moshpit participation. By engaging in moshpit practices alongside the female participants and allowing them to critically reflect on their own embodied experiences of being an avid mosher, a more nuanced perspective may emerge of what it feels like to be a female, transgressor and mosher.

\section{'You're a Woman?': Transgressing the Moshpit}

As I observed and held my ground on the edge of the pit I noticed a small woman, bright blonde hair with faded blue highlights, bouncing in and between the black-clad mass of men's bodies. She suddenly got slammed in between two large masculine bodies, was sucked into the core of the pit but emerged again near the front of the stage. Gracefully she weaved her way in and out of the pit, a mesmerising display of embodied subcultural knowledge, dedication and skill. I spotted another woman in the pit so I jumped in...we quickly made eye contact. She put her arm around my waist and we headbanged in unison while bumping into other forcible bodies. Some of the men returned to the side of the pit, eying our movement. I felt like they were suspicious of our presence, as if we were alien entities that were disrupting the typical masculine rhythms that dictated the pit. They seemed unsure if they should push us back or to refrain for fear of causing us ostensible harm (Author 1, field notes, March 2012).

Members within the Leeds extreme metal music scene share values, norms, and behaviours that highly esteem notions of masculinity. In Gruzelier's (2007) analysis of the valorisation of masculine solidarity within moshpit practices, he accounts for the ways that moshpits are spaces that encourage male homosocial interaction. There are clearly strong associations between masculinity and moshing when one examines the male bias of the gender demographic and the aggressive gestures found in the pit. These homosocial bonds are dismantled when women immerse themselves in the pit; consequently, when the women's gender identities became noticeable men would strengthen their "ownership" (Krenske and McKay 2000) of the space by lifting them out or forcefully pushing them to the peripheries:

It's true, like, until there's a break in the song and everyone turns around and they're like 'wow'. And sometimes people do look at you and are like, 'what, you're a woman? You just pushed me!' There have been occasional times where people have like repeatedly lifted me out. Like men push you back sometimes....Like they would push me out of the pit continuously and it's like 'dude, I want to be here. If I couldn't handle it I wouldn't be there (Allison). 
This physical form of exclusion also resonated with Carole's experiences of when she first started moshing:

There have been a couple of instances where men have been hesitant to push me.

You're there looking around, everyone is bouncing while you're stuck in this little circle.

So you actually have to go out there and push people. l've ended up being pushed to the back of the pit because moshpits are for 'men'. Big men, big sweaty men with large beer guts [laughs aloud while rolling her eyes].

Interestingly Carole acknowledged the masculinised spectacle of the moshpit and the ways in which female transgression can be quickly disabled by men. But by participating in the pit alongside Carole, Author 1's presence made it more difficult for men to marginalise our movements. On numerous occasions Carole and Author 1 have moshed together at local gigs - holding onto each other, pushing each other, talking in between songs while remaining in the middle of the pit - which expanded their spatial liberties while destabilising men's ability to dominate the pit. This is what makes a moshography such an exciting and powerful methodological practice.

Similarly Hutcherson and Haenfler's (2010) research about extreme metal found that males who successfully enacted "appropriate" extreme metal masculinity were located in central areas of the moshpit while men perceived to be less masculine were positioned on the margins of the pit area, along with the women. Yet none of the female moshers in this study were willing to accept their relegation to the fringes. If they were pushed to the edge they would forcefully jump back in. They were challenging assumptions based on hegemonic norms that women were not physically able to hold their own in the pit or that they did not have the capacity to acquire the appropriate skills to mosh. Some of the women commented that men would be overly protective when women entered the space. This is echoed by Shelly: "Yeah but there have been times where people have tried to shield you a little bit because they think 'aww she's a woman and she can't throw or whatever, she can't throw her own weight against someone'”.

However, women's ability to successfully transgress and immerse themselves in the pit was undermined when men took advantage of their anonymous position in the moving space. A few of the female moshers admitted that they had experienced some form of sexual abuse or physical intrusion by male fans, specifically when stage diving and crowd surfing. Women's bodies become vulnerable as they are touched, groped, carried, and moved over the audience members:

In a couple of instances when I have stage dived or whatever, you have got the weirdoes who try to like feel your bum or something and it's like, good job I can't see your face right now because my fist would probably be in it. Actually, yes, in the stage diving sense, the occasional times I have done...urm people are more eager to catch ya. It does seem like people are like 'oh a girl, must catch' sort of thing (Hannah).

Within this one account the contested nature of the subcultural spectacle is illustrated. On one hand the extreme metal spectacle and its participants reinforce notions of hegemonic masculinity and femininity, emphasising that women are 'sex objects' which places limits on women's ability to transgress the moshpit. On the other hand, Holly indicates that because she is a woman men are more likely to be courteous, attentive and supportive of her transgressive performance of stage diving.

\section{Jump and l'll Catch You: Being a Female Stage Diver}

...people suddenly started to jump on stage as the floor rumbled beneath them. They remained there for a few seconds, singing, dancing while scanning the crowd for a safe leap. I saw one woman, small with black hair, crawl up on stage. She stood there, her smile infectious... with no indication she jumped off the stage into the crowd of heaving bodies, moving back and forth. Anonymous hands carried her stomach first across the 
room... she rolled and twisted her body with each pass. Then another woman, Carole, got up on stage. She raised her arms to give the crowd the horns. Quickly she turned her back to the crowd, stuck her arms out to her side, placed her feet together and allowed herself to fall... (Author 1, field notes, May 2012).

For the majority of the female moshers stage diving was considered to be the most risky and transgressive form of moshing. Stage diving is the courageous act of jumping off a stage into the crowd below while anticipating that audience members will successfully catch the jumper. As audience members extend their arms to prevent the jumper from falling to the ground this practice swiftly transforms into crowd surfing, where the jumper is carried above the crowd. Women such as Shelly, Allison and Hannah thought that stage diving and crowd surfing should be deployed for special occasions, reserved for their favourite band and for large metal music festivals. Stage diving heightens women's visibility during a metal gig as they demand attention and support from the audience. This is echoed in Shelly's account of her stage diving experiences:

I think, not everyone gets the chance to do it, but it's definitely a lot different, completely different. I mean you still got that trust sense there because when you're crowd surfing everyone's kind of holding you up and looking out for you. Because you're above everyone else, it's a totally different point of view and it's not like you're in there for a whole show, you just do it once and then it's over, so it's a very quick thing that happens. It kind of feels strange because everyone's looking, you know everyone's looking at you while you do it as well.

Women stage divers, then, are physically invading the predominantly masculine space of the moshpit with and through their bodies. The amplified visibility of female stage divers participating in the extreme metal spectacle morphs into its own gendered spectacle. Stage diving becomes a public display of transgression, resistance, play, and subcultural identity performativity which demands responsiveness from the entire crowd.

Hannah, who frequently is invited by metal bands to come up on stage and be part of the stage act, participated in stage diving despite the potential for serious injury. It is a practice that challenges hegemonic norms of how women should use their bodies and the female jumpers' reading of the crowd. In Driver's (2011: 979) exploration of embodied subcultural identities in the Gold Coast hard-core scene, he put forth that perceptions of authentic membership are very much "bound up in one's embodiment of specific kinds of knowledge and understanding". As Hannah describes her stage diving experiences, her embodied knowledge of how to read a crowd is essential to a successful jump:

I'm not scared because there are people willing to catch you. And I'm not some huge guy with a beer belly the size of a small planet so I'm okay. But I'm not going to jump into an empty gap or anything like that. I always make sure a couple of people are aware that I'm gonna jump when I do otherwise it leads to a massive injury. I've seen a couple of people sprain their arms and stuff like that, it's just like...it's not good but it's not going to stop me.

For all of the female moshers interviewed, it was the exhilaration, the adrenaline rush and the intimate connection with other people in the crowd that make stage diving such an affective moshing practice:

....t's almost like, for two seconds you catch somebody's eye, and for those two seconds you're the best of friends in the world. And then when you're up on stage, when you're about to throw yourself off, you catch their eyes and you can see that they're going to catch you so you can launch yourself off and everything will be great (Carole)

When women participate in stage diving and crowd surfing practices they require attention, trust and respect from the predominantly male crowd. They become visible actors in the spectacle that typically renders them invisible. And even with the threat of serious injury these women are smiling as they take that audacious leap, actively turning their worlds upside down as they roll and twist across a sea of hands. They are 
freeing themselves from their restricted corporeal and spatial limitations constructed and reified by the masculinised metal scene (Krenske and McKay 2000) and disrupting the homosocial space of the moshpit one jump at a time.

\section{Conclusions}

This paper comes out of an on-going moshography, which has at its heart questions about the purpose of leisure and popular music in the contemporary world. We have in this article focussed our attention on transgression, embodiment and the notion of the spectacle in the spaces of the extreme metal scene in Leeds. It is our contention that such spaces, like the moshpit, are subject to a number of contestations of meaning. We have shown that such negotiations of meaning in the moshpit are inextricably connected to the wider issues of hegemonic control and constraint in modern society. Transgression and spectacle, then, are context-dependent. We've demonstrated that spectacles are multifaceted, dynamic and contested territories. Within the subcultural spectacle of extreme metal, visible, transgressive moshpit practices such as stage diving are not only situated within the larger musical spectacle but transform into public spectacles of resistance, courage and gendered transgression. However the capacity for women to transgress was undermined when they were forced to the peripheries and inappropriately touched, reinforcing the idea that the pit is a site of hegemonic control and masculine solidarity.

The question of agency is central to both Debord (1967) and Maffesoli's (1996) account of the spectacle and the way in which it enables resistance and transgression. We suggest that although extreme metal is potentially a site for a polyvalent reading of performativity and transgression, such readings are only intrinsic to the extreme metal scene, and as such their transformative potential in wider society remains uncertain. Finally, we argued that a moshography grapples with issues of the nonrepresentational, embodied aspects of being an active participant of a subculture, and fleshes out the feelings and sensations of disrupting space through corporeal performativities of gender. We aimed to explore and uncover the "multiplicity of ways musics [and music practices] are experienced, produced, reproduced and consumed" (Revill 2004: 202) on and through the body. A moshography is distinct from more conventional qualitative methods, in that it brings the body and the rawness of embodiment back into subcultural studies through written accounts of physicality within the moshpit. The use of a moshography was crucial in understanding women's experiences in moshpit practices because it is through the embodied practice of moshing that embodied knowledges are produced along with understandings of our bodies and the social order.

Engaging in moshpit practices alongside her female participants and allowing them to critically reflect on their own embodied experiences of being an avid mosher, Author 1 developed a more nuanced, multivocal perspective of what it feels like to be a female within a predominantly male scene. A moshography also allowed deeper engagement with the sensations involved when being swallowed up and churned within an aggressive, moving space. This approach encourages ethnographers who are studying youth, popular music, and/or subcultures to be less wary of the creative or the corporeal, and to embrace the messiness of everyday life as it continually unfolds, erupts and produces interweaving pathways of becoming. Furthermore, the moshpit is a significant site of study because it is a complex space where some norms are transgressed while others are transformed. Through corporeal encounters hegemonic gender norms are continually contested and reproduced, while conventional expectations of bodily interactions and social conduct are transgressed and transformed through the succession of clashing bodies. Finally, we offered an account of the ways in which transgression, identity, gender, performance, and spectacle intersect and overlap within the context of the Leeds extreme metal music scene in 
order to illustrate the significance moshing practices play in the lives of female extreme metal fans.

\section{Bibliography}

Alim, H. S. (2007) Critical Hip-Hop Language Pedagogies: Combat, Consciousness, and the Cultural Politics of Communication. Journal of Language, Identity, and Education, 6(2): 161-176.

Ambrose, J. (2001) Moshpit: The Violent World of Mosh Pit Culture. London: Omnibus Press.

Bataille, G. -

(1989) The Tears of Eros. Paris: City Lights Books.

(1986) Erotism: Death and Sensuality. New York: Walker and Company.

Berger, H.M. (1999) Metal, Rock, and Jazz: Perception and the Phenomenology of Musical Experience. Hanover: Wesleyan University Press.

Bertrand, M. (2000) Race, Rock, and Elvis. Champaign-Urbana: University of Illinois.

Bogue, R. (2004) Deleuze's Wake: Tributes and Tributaries. USA: State University of New York.

Bramham, P., and Wagg, S. (2009) Sport, Leisure and Culture in the Postmodern City. Aldershot: Ashgate.

Broek, M. (2012) Hawthorne, Madonna, and Lady Gaga: The Marble Faun's Transgressive Miriam. Journal of American Studies, 46(3): 625-640.

Cohen, S. (1993) Ethnography and Popular Music Studies. Popular Music, 12(2): 123138.

Cooley, T. J., and Barz, G. (2008) Casting Shadows: Fieldwork is Dead! Long Live Fieldwork! In G. Barz and T. J. Cooley (Eds.) Shadows in the Field: New Perspectives for Fieldwork in Ethnomusicology. $2^{\text {nd }}$ Edition. London: Oxford University Press: 3-24.

Dawkins, M.A. (2010) Close to the Edge: The Representational Tactics of Eminem. The Journal of Popular Culture, 43(3): 463-485.

Debord, G. (1967) Society of the Spectacle. New York: Zone Books.

Denzin, N. K. (2002) Reading Race: Hollywood and the Cinema of Racial Violence. London: Sage.

Denzin, N. K., and Lincoln, Y. S. (2007) Sage Handbook of Qualitative Research. London: Sage.

Diversi, M. (1998) Glimpses of Street Life, Qualitative Inquiry 4(2): 131-147.

Driver, C. (2011) Embodying Hardcore: Rethinking "Subcultural" Authenticities. Journal of Youth Studies, 14(8): 975-990.

Duffy, M. (2005) Performing Identity Within a Multicultural Framework. Social \& Cultural Geography, 6(5): 677-692.

Duncum, P. (2009) Toward a Playful Pedagogy: Popular Culture and the Pleasures of Transgression. Studies in Art Education: A Journal of Issues and Research, 50(3): 232-244.

Flannery, M. C. (2001) Quilting: A Feminist Metaphor for Scientific Inquiry. Qualitative Inquiry, 7(5): 628-645.

Gilman-Opalsky, R. (2008) Guy Debord and Ideology Materialised: Reconsidering Situationist Praxis. Theory in Action, 1(4): 5-26.

Gruzelier, J. (2007) Moshpit Menace and Masculine Mayhem. In F. Jarman-Ivens (Ed.), Oh Boy! Masculinities and Popular Music. London: Routledge: 58-75. 
Halnon, K.B. (2004) Inside Shock Music Carnival: Spectacle as Contested Terrain. Critical Sociology, 30(3): 743-779.

Hjelm, T., Kahn-Harris, K., LeVine, M. (2012) Heavy Metal as Controversy and Counterculture. Popular Music History, 6(1-2): 5-18.

Holman Jones, S. (2002) The Way We Were, Are, and Might Be: Torch Singing as Autoethnography. In Y. S. Lincoln \& N.K. Denzin (Eds.), Turning Points in Qualitative Research; Tying Knots in a Handkerchief. Blue Ridge Summit USA: Alta Mira Press: 105-118.

Hutcherson, B. (2009) Moshing and Thrashing and Headbanging (Oh My!): Gender, Genre and Authenticity in the Extreme Metal Subculture. Thesis Presented for the Masters of Arts Degree. University of Mississippi: USA.

Hutcherson, B., and Haenfler, R. (2010) Musical Genre as a Gendered Process: Authenticity in Extreme Metal. Studies in Symbolic Interaction, 35: 101-121.

Hutton, F. (2006) Risky Pleasures? Club Cultures and Feminine Identities. Aldershot: Ashgate.

Janesick, V. J. (1998) The Dance of Qualitative Research Design: Metaphor, Methodolatry, and Meaning. In N. K. Denzin \& Y. S. Lincoln (Eds.), Strategies of Qualitative Inquiry. London: Sage: 35-55.

Kahn-Harris, K. (2007) Extreme Metal: Music and Culture on the Edge. Oxford: Berg.

Kellner, D. (2003) Media Spectacle. London: Routledge.

Klypchak, B. (2012) "How You Gonna See Me Now": Recontextualizing Metal Artists and Moral Panics. Popular Music History, 6(1-2): 38-51.

Krenske, L., and McKay, J. (2000) "Hard and Heavy": Gender and Power in a Heavy Metal Subculture. Gender, Place and Culture, 7(3): 287-304.

Lashua, B.D., and Fox, K.M. (2007) Defining the Groove: From Remix to Research in The Beat of Boyle Street. Leisure Sciences, 29(2): 143-158.

Lau, T. J. (2005) Jump!: Aggression, Dance and Gender Roles - A Reading of Mosh Pit Culture. Candidate Thesis for Department of Musicology. University of Oslo: Norway.

Leblanc, L. (1999) Pretty in Punk: Girls' Gender Resistance in a Boys' Subculture. New Brunswick, NJ: Rutgers University Press.

Lemish, D. (2003) Spice World: Constructing Femininity the Popular Way. Popular Music \& Society, 26(1): 17-29.

Lucas, C. (2010) White Power, Black Metal and Me: Reflections on Composing the Nation. In R. Hill and K. Spracklen (Eds.) Heavy Fundametalisms: Music, Metal and Politics Oxford: ID Press: 43-53.

Maffesoli, M. (1996) The Time of the Tribes: The Decline of Individualism in a Mass Society. London: Sage.

Morton, F. (2005) Performing Ethnography: Irish Traditional Music Sessions and New Methodological Spaces. Social \& Cultural Geography, 6(5): 661-676.

Oldfather, P., and West, J. (1994) Qualitative Research as Jazz. Educational Researcher, 23(8): 22-26.

Overell, R. (2012) "[l] Hate Girls and Emo[tion]s": Negotiating Masculinity in Grindcore Music. Popular Music History, 6(1-2): 198-223.

Palmer, C. T. (2005) Mummers and Moshers: Two Rituals of Trust in Changing Social Environments. Ethnology, 44(2): 147-166.

Purcell, N. J. (2003) Death Metal Music: The Passion and Politics of a Subculture. London: McFarland \& Company Publishers.

Revill, G. (2004) Performing French Folk Music: Dance, Authenticity and Nonrepresentational Theory. Cultural Geographies in Practice, 11: 199-209. 
Riches, G. (2011) Embracing the Chaos: Mosh Pits, Extreme Metal Music and Liminality. Journal for Cultural Research, 15(3): 315-330.

Roberts, T. (2011) Michael Jackson's Kingdom: Music, Race, and the Sound of the Mainstream. Journal of Popular Music Studies, 23(1): 19-39.

Schlit, K. (2003) "A Little Too Ironic": The Appropriation and Packaging of Riot Grrrl Politics by Mainstream Female Musicians, Popular Music \& Society, 26(1): 5-16.

Simon, B.S. (1997) Entering the Pit: Slam-Dancing and Modernity. Journal of Popular Culture, 31(1): 149-176.

Sparkes, A. C., and Smith, B. (2012) Embodied Research and Methodologies and Seeking the Senses in Sport and Physical Culture: A Fleshing Out of Problems and Possibilities. Research in the Sociology of Sport, 6: 167-190.

Spracklen, K., Lucas, C., and Deeks, M. (2012) The Construction of Heavy Metal Identity Through Heritage Narratives: A Case Study of Extreme Metal Bands in the North of England. Popular Music and Society, 37(1): 1-15.

Spracklen, K. (2010) Gorgoroth's Gaahl's Gay! Power, Gender and the Communicative Discourse of the Black Metal Scene. In R. Hill and K. Spracklen (eds.) Heavy Fundamentalisms: Music, Metal and Politics. Oxford: ID Press: 89-102.

Spry, T. (2010) Call it Swing: A Jazz Blues Autoethnography. Cultural Studies <=> Critical Methodologies, 10(4): 271-282.

Stoller, P (1997) Sensuous Scholarship. Philadelphia, PA: University of Pennsylvania Press.

Thrift, N. (2007) Non-Representational Theory: Space, Politics, Affect. London: Routledge.

Tomlinson, A. (2002) Theorising Spectacle: Beyond Debord. In J. Sugden and A. Tomlinson (Eds.) Power Games: A Critical Sociology of Sport. London: Routledge: 44-60.

Tsitsos, W. (1999) Rules of Rebellion: Slamdancing, Moshing, and the American Alternative Scene. Popular Music, 18(3): 397-414.

Williams, P. J. (2011) Subcultural Theory: Traditions and Concepts. Cambridge: Polity Press. 